\title{
Zoonosis, epidemias y cambio climático ${ }^{1}$ \\ Zoonosis, epidemic and climate change
}

\author{
Paulina Rivero Weber \\ Facultad de Filosofía y Letras \\ Universidad Nacional Autónoma de México | México \\ Contacto: paulinarivero@filos.unam.mx
}

\section{Resumen}

Las epidemias han acompañado a la humanidad a lo largo de toda su historia y han recibido diversas explicaciones. En Grecia clásica se atribuían a los disgustos entre los dioses; el judeocristianismo las atribuyó a los pecados de la humanidad. Hoy la ciencia da explicaciones claras, pero la humanidad no actúa en consecuencia. El problema es que las pandemias son los únicos eventos que superan a las guerras en pérdidas y, de entre ellas, el $70 \%$ se debe a zoonosis: eso indica que debemos relacionarnos de otra manera con los animales. Si a ello agregamos que nuestro trato hacia ellos ha tenido como consecuencia el aceleramiento del cambio climático, de todas nuestras obligaciones éticas, cambiar nuestra conducta para con los animales es la más urgente. Más allá de la compasión, urge un trato diferente para todos los seres sintientes.

Palabras clave: pandemias, pérdidas, zoonosis, ética, animales, compasión, seres sintientes

\begin{abstract}
Epidemics have accompanied humanity throughout its history and have received various explanations. In classical Greece they were attributed to the troubles between the gods; Judeo-Christianity attributed them to the sins of humanity. Today science gives clear explanations, but humanity does not act accordingly. The problem is that pandemics are the only events that surpass wars in losses, and among them, $70 \%$ are due to zoonoses: this indicates that we must relate in another way with
\end{abstract}

\footnotetext{
${ }^{1}$ Artículo por invitación.
} 
animals. If we add to this that our treatment of them has resulted in the acceleration of climate change, of all our ethical obligations, changing our behavior towards animals is the most urgent. Beyond compassion, there is an urgent need for different treatment for all sentient beings.

Keywords: pandemics, losses, zoonoses, ethics, animals, compassion, sentient beings

Cargado de maravillosos tesoros, el sacerdote Crises llegó hasta las naves de los griegos que tenían sitiada Troya, con la intención de recuperar a su hija, a quien el rey griego había secuestrado. Cuenta Homero que el viejo sacerdote portaba en las manos las ínfulas de Apolo y en su nombre exigió la liberación de la doncella. Pero Agamenón, el orgulloso rey de los griegos, se negó a devolverla. Derrotado, Crises suplicó a Apolo un castigo para los griegos y, en respuesta, el dios desató una terrible epidemia; fue la tremenda peste que colocó a los griegos a punto de perder la guerra. Todo esto se narra en la primera página de la primera obra escrita de la cultura occidental: La Ilíada. ${ }^{2}$

Las epidemias han acompañado a la humanidad desde sus orígenes y en este trabajo reflexionaremos sobre las enseñanzas que la epidemia causada por el virus SARS-COV-2 puede y debe dejar a la humanidad. Sobre el origen de las epidemias y de todos los males humanos, ya Eric Robertson Dodds en su magna obra Los griegos y lo irracional, ${ }^{3}$ ha analizado la forma en que los antiguos griegos empleaban a sus dioses para explicar las enfermedades: todos sus bienes y sus males dependían de aquellos seres olímpicos (Dodds, 1996: 71). Ellos eran los responsables de cuanto sucedía en la Tierra y eran, decía Nietzsche (1985: 51-55), como un espejo que reflejaba al ser humano con todos sus defectos y virtudes. Esta forma de entender el mundo no era, por supuesto, exclusiva de los griegos: en muchas otras culturas sucedía lo mismo. Pero en los griegos encontramos la primera mención a una epidemia histórica y, por ello, nos parece ejemplar para comprender la evolución en el entendimiento de una epidemia.

\footnotetext{
2 Para el significado de loimós como plaga y pestilencia a la vez, al igual que sucede con el vocable “peste” en castellano, véase Liddell y Scott (1843: 1060). Para la versión bilingüe, véase Homero (1991: 2).

${ }^{3}$ La idea se encuentra a lo largo de todo el texto como pilar y sostén fundamental de este clásico estudio de Dodds (1996): la aparente racionalidad del arte griego, de su pensamiento o de cualquier otro aspecto, esconde una serie de factores irracionales, diferentes uno del otro, que Dodds (1996: 71 90) analiza en dicha obra.
} 
Se trata de un dato histórico: no olvidemos que La Ilíada narra hechos que ocurrieron hacia el segundo milenio antes de nuestra era, mismos que se transmitieron por siglos de manera oral, hasta que comenzaron a escribirse en el siglo virI. Hoy en día, después de las excavaciones de Frank Calvert en 1865 y, a partir de él, las de Heinrich Schliemann en 1871, ya nadie puede dudar de la realidad histórica de aquella epidemia a la que se refiere La Ilíada ni del sitio que hoy es, por cierto, Patrimonio de la Humanidad por la excepcional importancia cultural y por la "influencia de La Ilíada de Homero en las artes creativas durante más de dos milenios” (UNESCO, s. f.).

Para explicar aquella epidemia de la historia occidental, los dioses fungieron como el asilo de la ignorancia humana, como diría Spinoza (2020: 72) en su Ética. Y por muchos, muchos siglos más, los dioses continuaron teniendo un fuerte protagonismo en el origen de las epidemias y las pandemias. Tiempo después, lo que para los griegos era responsabilidad de dioses parciales, envidiosos y egoístas, para el judeocristianismo se transformó en el castigo divino de un dios perfecto para los pecados de una humanidad imperfecta y siempre culpable.

Por siglos, a nadie se le hubiera ocurrido que el origen de una epidemia se encontrara en un pequeńísimo bicho de apenas unos 10 nanómetros que, a pesar de su tamaño, arrase con poblaciones enteras. Mucho menos se hubiera pensado entonces que ese pequeñísimo bicho ni siquiera estuviera propiamente vivo, sino que permaneciera, como lo ha explicado Antonio Lazcano (2010: 73-84), formando la borrosa línea entre lo vivo y los entes sin vida. Del griego iós, que significa toxina o veneno, la palabra "virus" designa a los agentes acelulares que solamente pueden reproducirse en las células de un organismo vivo. En realidad, los virus son moléculas, ya sea de ADN o de ARN y proteínas, que logran que la célula infectada reproduzca nuevos virus. El primer virus descubierto fue el del mosaico del tabaco, en 1930, pero hoy sabemos que existen miles de ellos y hay quienes consideran que son millones.

Lo que hizo diferente a la pandemia de la COVID-19, causada por el coronavirus SARS-COV-2, fueron básicamente dos cuestiones: en primer lugar, esta pandemia arribó a un mundo globalizado en donde las conexiones entre todos los países no sólo son rápidas, sino continuas, y lo son en todos los rincones del mundo. Lo anterior, como es natural, contribuye a una diseminación intensiva del virus. Pero, por otro lado, es la primera gran pandemia por la que atraviesa la humanidad en su conjunto, bajo la luz de la ciencia. Nunca se había globalizado una epidemia en esta era científica, en la que podemos dejar de buscar las oscuras causas de las enfermedades en dioses caprichosos, vengativos o justicieros. Hoy, hasta el más ignorante individuo, ajeno por completo a la ciencia, puede observar el virus a través 
de fotografías en periódicos o en redes sociales: se acabó el misterio. Los científicos investigan activamente tanto su forma de proceder como la posibilidad de curarlo y prevenirlo por medio de una vacuna.

Pero existe un cierto saber que investigan tanto las ciencias como las humanidades y que debemos reflexionar: su origen. Al respecto, la ciencia ilumina el presente, pero también el pasado; si bien no podemos saber exactamente qué tipo de epidemia arrasó con las huestes griegas frente a Troya, sí sabemos mucho acerca de las pandemias a lo largo de la historia de la humanidad, lo que permite comprender mejor el origen de las pandemias y cómo evitarlas o prevenirlas: ciencia, historia y filosofía han arrojado una nueva luz en torno a este tema.

Hoy sabemos que las pandemias han sido los únicos eventos que superan en pérdidas a cualquier guerra, pues los virus son depredadores sumamente efectivos de la humanidad. Pero sabemos algo de suma importancia: la influenza aviar, la influenza porcina, la encefalitis espongiforme bovina, el VIH, la peste negra y el actual coronavirus, entre muchas otras epidemias, se consideran, por su origen, "zoonóticas", enfermedades que son definidas por la OMS como "un grupo de enfermedades infecciosas que se transmiten de forma natural de los animales a los seres humanos. El mayor riesgo de transmisión de enfermedades zoonóticas se produce en la interfaz entre el ser humano y los animales a través de la exposición directa o indirecta a los animales, los productos derivados de estos (por ejemplo, carne, leche, huevos) o su entorno" (OMS, s. f.).

Hoy los estudiosos de las pandemias y epidemias consideran que alrededor del $70 \%$ de ellas ha tenido su origen en los animales. Las zoonosis aparecen y reaparecen en la historia de las epidemias: hemos conocido ya varias epidemias de origen aviar, porcino o bovino. Aves, cerdos, ratas, primates, murciélagos o pangolines parecen indicarnos que el ser humano no posee la constitución biológica adecuada para convivir de manera cercana con otros animales sin correr cierto peligro. Y parecen indicarnos también que comer animales es una costumbre peligrosa. Si nos detenemos a pensar, veremos que incluso los animales que más han convivido con el ser humano a lo largo de su historia y desde su prehistoria, como el perro y más recientemente el gato, requieren ser vacunados para vivir de manera sana cerca del ser humano, en la misma medida en que requieren de cierta higiene para proteger tanto a quienes habitan con ellos como a ellos mismos.

En este punto quisiera formular una pregunta: ¿para qué sirve el increíble avance científico en la investigación sobre el origen de las epidemias o las pandemias? ¿De qué sirve saber que no es Apolo ni Zeus, como creían los griegos, o que no es un castigo al pecador, como lo llegaron a creer los cristianos? ¿De qué sirve si no hacemos caso, si no atendemos lo que ese conocimiento está indicando? Sólo sa- 
biendo de dónde proviene una enfermedad es posible prevenirla. En ese sentido, deberíamos de tomar conciencia de lo que implica que tantas epidemias tengan como origen el contacto con animales, en particular con una finalidad alimenticia, que hoy resulta completamente innecesaria e incluso perjudicial para el individuo y para el planeta en su conjunto. Pero expliquemos paso a paso lo recientemente dicho. El ser humano ya no requiere alimentarse de animales pues puede sustituir la proteína animal con otro tipo de dieta; de hecho, la ingesta de carne, en la medida en la que actualmente suele hacerse en gran parte del mundo, es más que dañina, mortal, como lo mostraremos. Hacia 1970 esta idea comenzó a ser respaldada por científicos que insistían en que la proteína animal, al igual que la grasa, puede ser nociva para la salud, mientras que no existe aún una enfermedad asociada a la ingesta de frutas, verduras, granos, leguminosas y demás alimentos de un origen ajeno al animal (Trapp y Barnard, 2010).

Los dos tipos de animales con los que podemos mantener relaciones peligrosas son los de granja y los silvestres. En cuanto a los primeros, los animales de granja no sólo han sido origen de gripes como la aviar o la porcina, también son transmisores de muchas enfermedades parasitarias comunes como la Taenia saginata o gusano plano de carne de res, la Taenia solium o gusano plano de carne de cerdo, la giardiosis, toxoplasmosis, triquinosis, cisticercosis, entre muchas otras (Departamento de Agricultura de Estados Unidos, 2011). Y por supuesto, cuando el ganado o las aves que se ingieren son sanas, bastaría pensar en la cantidad de antibióticos que el animal ha recibido en cautiverio para al menos disminuir su consumo. Porque podemos estar seguros de que los animales en cautiverio o bien se enferman, o bien han ingerido una cantidad de antibióticos que no es sana ni para ellos, ni para quien los ingiere. En cuanto a los animales silvestres, la pandemia causada por el coronavirus SARS-COV-2 debería ser un foco rojo en la historia de la humanidad: muchos animales silvestres pueden ser portadores de virus que a ellos no les resultan dañinos, pero que, en caso de llegar al ser humano de manera directa o por medio de otro vector, pueden ser tremendamente peligrosos.

La epidemiología actual ofrece suficiente información como para cuestionar nuestras relaciones con los animales y nuestra conducta alimenticia, al menos en dos aspectos fundamentales: por un lado, en cuanto al hecho de ser carnívoros, por el otro, en cuanto al trato que les hemos dado y nuestra cercanía con ellos. Pero de nada sirve el conocimiento científico si no actuamos a partir de él, esto es, si no somos capaces de transformar nuestras acciones éticamente para el bien común, para el bien del planeta en su conjunto. Pues nuestra forma de relacionarnos con los animales, aparte de generar enfermedades de muy diversa índole al ser humano, ha dañado también al planeta. Sucede que para que un porcentaje mínimo de la 
población consuma carne, el ser humano arrasa con selvas, bosques y todos los animales silvestres que los habitan. Día a día la vida silvestre se apaga y, como señala el macro-historiador Yuval Noah Harari, "la humanidad se ha apoderado del mundo" (2014: 385). Somos los responsables del desastre ambiental; al no valorar la vida de los animales silvestres, hemos invadido y destruido sus hábitats con sembradíos de monocultivos para la alimentación del ganado de la industria cárnica. Esa ha sido la receta del desastre, con la cual hemos acabado con enormes territorios de selva y bosques que albergaban una biodiversidad inimaginable. Todo lo que ahora es monocultivo para alimentar ganado, no sólo desplazó o extinguió grandes especies; también ha afectado la vida de millones de insectos de los que dependía la polinización. Por si eso fuera poco, esos mismos monocultivos que se siembran para alimentar ganado, requieren una inmensa cantidad de agua, que es el líquido del cual depende toda la vida. A lo anterior, como parte de la desastrosa receta, hemos de agregar los fertilizantes y los fumigantes que se emplean en dichos cultivos, así como las heces y los orines de millones de animales de ganado, que no desaparecen por arte de magia: se van a los ríos y de ahí, al mar. Y por supuesto: los gases del complejo aparato digestivo del ganado bovino, hoy lo sabemos, son un peligro para el medio ambiente. Los datos duros de la ciencia nos hacen ver que la cría de ganado vacuno genera alrededor de entre el $40 \%$ y el $50 \%$ del dióxido de carbono. Del total de los gases con efecto invernadero, si bien existen diferentes cálculos, lo que produce la industria ganadera oscila entre el $30 \%$ y el $18 \%$, contra el $13 \%$ generado por todos los transportes terrestres, marítimos y aéreos inventados por el hombre (LEAD y FAO, 2006). Lo anterior se debe a que los bovinos destacan entre el resto de los animales de ganado por su proceso digestivo, en el cual producen una gran cantidad de metano, que es sumamente destructivo, e incluso hay quienes lo consideran más dañino que el dióxido de carbono que emiten los vehículos, pues tiene un potencial de calentamiento global mayor que el dióxido de carbono.

Lo curioso es que este fenómeno, al igual que el origen de las enfermedades zoonóticas, ha sido estudiado, explicado y comprobado en muchas universidades, entre ellas la UNAM, pero no tiene mayor resonancia en la sociedad: ¿no son claras las implicaciones éticas de este fenómeno? ¿Por qué insistir en alimentarnos de algo capaz de causar enfermedades, crear epidemias y, por si fuera poco, destruir al planeta? Los monocultivos para alimentar a estos animales son tratados como si fueran lo más importante del planeta, cuando en realidad lo están destruyendo: hemos acabado con todos los recursos naturales con la única finalidad de que unos pocos consuman carne de ganado. Y con los pocos animales silvestres que quedan después de la destrucción de sus hábitats, lo único que se nos ocurre hacer es ca- 
zarlos, comerlos o apresarlos para un zoológico. Y aún así, nos consideramos animales inteligentes y "moralmente superiores".

¿No debe ser ya el momento de detenernos a examinar la relación que debemos tener con el resto de los habitantes del planeta? Es evidente que apelar al derecho que cada uno de los animales tiene para vivir su vida no es un argumento que la gente esté dispuesta a escuchar. Y en ese sentido, de nada sirve apelar a las obligaciones directas que debemos tener para con ellos. En lo personal, me queda claro que tenemos obligaciones directas para con todos los animales; me queda claro que, como lo dice el doctor José Sarukhán, ${ }^{4}$ hemos coevolucionado con ellos y tenemos por lo mismo una corresponsabilidad: el mundo no nos pertenece; le pertenece a la biodiversidad que ha coevolucionado por milenios.

Pero ya que esas obligaciones directas no encuentran aceptación en la población, quizá debamos entonces proceder de otra manera, y comenzar a hablar también de lo que Kant consideró las obligaciones que tenemos para con los animales no por ellos mismos, sino por nosotros, los seres humanos, pues para él, "respecto a la parte viviente, aunque no racional de la creación, el trato violento y cruel hacia los animales se opone mucho más íntimamente al deber del hombre hacia sí mismo" (Kant, 1999: 309-310). Esto es: debemos tratar bien a los animales por un deber para con nosotros mismos. Todo parece indicar que el ser humano es ciego o insensible en lo que respecta a nuestras obligaciones para con los seres no humanos; incluyamos, pues, nuestras obligaciones indirectas, a saber, aquellas que debemos llevar a cabo hacia los animales por nosotros mismos y por nuestro propio bien. Esta no es, desde mi perspectiva, la mejor postura ética. De hecho, es una postura antropocéntrica, esto es, continúa poniendo al centro de todo al ser humano, como si solamente él fuera digno de ser respetado. En ese sentido, tener que esgrimir las obligaciones que tenemos para con los animales de manera indirecta, me parece lamentable. Pero si es la única que la humanidad está dispuesta a escuchar, no queda más remedio que emplearla como un arma en la lucha por el respeto a la biodiversidad y al planeta en su conjunto.

Con base en lo recién explicado, digamos, pues: "no debemos comer animales porque estamos acabando con el planeta, y si continuamos haciéndolo, no tendremos planeta en dónde vivir", o bien, "no debemos incluir animales en nuestra dieta porque no es bueno para nuestra salud", o "no debemos mantener en cautiverio a los animales porque éstos se enferman y nos vemos obligados a proporcionarles enormes cantidades de antibióticos que luego ingerimos", o "no debemos convivir en la misma casa o en el mismo lugar con animales exóticos porque existe la posi-

\footnotetext{
${ }^{4}$ Véase Programa Universitario de Bioética UNAM (2020).
} 
bilidad de que nos contagien enfermedades". Todas estas prohibiciones expresan obligaciones indirectas, pues no buscan cumplir éticamente con la vida de los animales, sino con la del ser humano. La doctora Julia Carabias ${ }^{5}$ coincide con estas ideas y considera que la pandemia actual debe transformarse en un acicate para reflexionar sobre nuestra relación con los animales. Esta pandemia, como muchas otras, tuvo su origen en una relación inadecuada del ser humano con los animales. No debemos comer ni debemos cohabitar con ciertos animales. ¿Cuáles? En realidad, la mayoría; de hecho, todos, menos aquellos que por siglos hemos domesticado, el perro y el gato. Y aun así, ya lo decía al inicio de este escrito, quien quiera convivir con un perro o un gato debe atenderlos: proporcionarles un lugar adecuado a sus necesidades, vacunarlos y mantenerlos limpios si no queremos que sean fuente de enfermedades.

Un dato más respecto a las zoonosis: la pandemia del coronavirus SARS-COV-2 puso en el centro de la discusión la existencia de los mercados húmedos. Pero éstos existen no sólo en China; lamentablemente en casi todas partes del mundo hay mercados húmedos en mayor o menor medida. ¿Qué es un mercado húmedo? La humedad a la que se refiere esta designación se origina en un dato grotesco: son mercados de animales vivos, destinados al consumo humano, donde los orines de éstos se mezclan con la sangre de los recientemente asesinados. Si lo pensamos, tener animales vivos que se matan frente a otros animales con absoluta insensibilidad, es un acto de increíble crueldad. En esos mercados se actúa como si el resto de los animales no se dieran cuenta de que se encuentran entre sangre y orines y que pronto morirán igual que el resto. ¿Cómo podemos llegar a tal crueldad? ¿Cómo pueden algunas personas superar el asco y la repulsión a un estado de insalubridad grotesco, entre excrementos, orines y sangre, con tal de comer carne?

Pero la realidad es que esto no sucede únicamente en los mercados húmedos. Cualquiera que se acerque a un rastro o a una fábrica de carne de aves, podrá constatar exactamente lo mismo. El terror de los animales que serán sacrificados hace que excreten heces y orines que se mezclarán con su sangre al morir. ¿Cómo hemos podido llegar a este grado de insensibilidad? En muchos casos, hemos llegado a esto porque logramos ocultar el dolor. La carne que la gente come, viene empaquetada de manera limpia, y ese paquete ha borrado las huellas del miedo; ha borrado las heces, los orines y la sangre. Ocultamos el dolor en supermercados limpios que en nada se asemejan al rastro de donde proviene esa carne de animal. El documental Cristal Walls (Paredes de cristal) se fundamenta en esa idea: si los rastros tuvieran paredes de cristal, nadie comería carne. Sin embargo, en otros

\footnotetext{
${ }^{5}$ Véase Radio UNAM (s. f.).
} 
casos, como sucede en los mercados húmedos en China, el dolor y sus huellas están ahí, frente al consumidor. En ese sentido tenemos que aceptar que la desensibilización se aprende, es un proceso educativo: al individuo se le puede educar en la crueldad y en la falta de sensibilidad. Ya lo decía Aristóteles (1983): el camino para adquirir una virtud es el mismo que se debe atravesar para adquirir un vicio (2833). A través de las costumbres podemos sensibilizar o desensibilizar a un individuo o a una sociedad. Nos acostumbramos a la crueldad de la misma manera en que nos acostumbramos a cualquier costumbre impuesta: a través de la cotidianidad. Nosotros y nuestros contemporáneos, ¿qué les enseñamos a los nińos en nuestras escuelas? Que las vacas "nos dan” su leche y su carne para alimentarnos, así como su piel para vestirnos. No queremos enfrentar que los seres humanos hemos hecho del mundo animal, como bien lo dijo Bashevis Singer, un eterno Treblinka. ${ }^{6} \mathrm{Y}$ en nuestra cómoda zona de confort nos aterra que en China se coman a los perros, pero comemos cerdos que son tan inteligentes y sensibles como cualquier perro o más.

Ahora bien, todo tiene un límite. Incluso las huestes de Hitler no fueron funcionales a la hora del máximo terror, cuando debían funcionar como una máquina de muerte. En parte por eso se crearon lugares de exterminio masivos; porque ni siquiera una vida dedicada a desensibilizar a sus soldados logró erradicar al $100 \%$ la sensibilidad en ellos. En ese sentido, quienes comen carne deberían tener el valor de visitar un rastro y enfrentar lo que están haciendo. Es muy probable que, después de una visita a estos lugares, dejaran de comer carne. Y si no hay quien lo haga, se deberá a que la elección de la mayoría no es ser éticos ni enfrentar la realidad sino lo contrario: hacer a un lado la ética y no ver la realidad. Insisto: la mayoría de la humanidad no quiere ver ni saber de los deberes directos para con los animales, pero quizá podamos actuar al menos por los deberes que de manera indirecta tenemos para con ellos. La obligación de no ser crueles con un animal, decía Kant (1999: 309-310) en La metafísica de las costumbres, debe seguirse como un deber "del hombre hacia sí mismo", y podríamos agregar: lo es por conservar buena salud y por conservar un planeta para poder vivir. Lo digo nuevamente: me parece lamentable tener que argumentar de esa manera, pero creo que la situación del planeta no está como para discusiones en torno a cómo argumentar y por qué hacerlo. Debemos actuar ya y convencer al mundo de la necesidad de respetar la vida de los

\footnotetext{
${ }^{6}$ Isaac Bashevis Singer (1991-1904,יצחק באשעווים זינגער) fue un escritor nacido en Polonia. Siendo judío, escribió casi toda su obra en idish. En ella deja ver la violencia antisemita y abunda en la comparación entre el trato que los nazis dieron a los judíos, por un lado, y el trato que los seres humanos hemos dado al resto de los animales, por otro. Bashevis Singer recibió el Nobel de Literatura en 1978. La cita mencionada aparece en Patterson (2002: 181-185).
} 
animales y la salud del planeta; no tenemos tiempo para darnos lujo alguno. Quienes no puedan ver, sentir o comprender las obligaciones que de manera directa tenemos para con los animales, que cambien su relación con ellos al menos por las obligaciones indirectas, aquellas que por beneficio propio debemos tener. Optar por esta forma de argumentar puede ser al menos un paso hacia una futura comprensión de nuestra verdadera obligación con los animales, a saber, el respeto que deberíamos tener para con todo ser sintiente; la vida debería ser reverenciada, amada o al menos, respetada: nada sensible nos debe resultar ajeno.

\section{Referencias bibliográficas}

Aristóteles. (1983). Ética nicomaquea. México: UNAM.

Departamento de Agricultura de Estados Unidos (USDA). (2011). Servicio de Inocuidad e Inspección de los Alimentos. Recuperado de https://www.fsis.usda. gov/wps/wcm/connect/aa9f4a55-2e6f-45a3-8953-d9e986bde1b9/Parasites Food Safety SP.pdf?MOD=AJPERES.

DodDs, Eric. Robertson. (1996). Los griegos y lo irracional. Madrid: Alianza.

Harari, Yuval Noah. (2014). De animales a dioses. Una breve historia de la humanidad, (Joandomènec Ros., Trad.). Barcelona: Debate.

Homero. (1991). La Iliada. Madrid: Biblioteca Clásica Gredos.

Kant, Immanuel. (1999). La metafísica de las costumbres. Madrid: Tecnos.

Lazcano, Antonio. (2010). “Origen y evolución de los virus: ¿Genes errantes o parásitos primitivos?”. Mensaje Bioquímico, 34, 73-84.

Livestock, Environment and Development, The (LEAD); Food and Agriculture Organization of the United Nations (FAO). Livestock's long shadow: environmental issues and options. (2006). Italia: Organización de las Naciones Unidas para la Agricultura y la Alimentación. Recuperado el 25 de septiembre de 2020 de http://www.fao.org/3/a0701e/a0701e.pdf.

Nietzsche, Friedrich. (1985). El nacimiento de la tragedia. Madrid: Alianza.

Organización de las Naciones Unidas para la Educación, la Ciencia y la Cultura (UNESCO). (1999). Convention concerning the protection of the world cultural and natural heritage. Recuperado de http://whc.unesco.org/archive/ repcom98.htm\#849.

Organización Mundial de la Salud (OMS). (s. f.). Inocuidad de los alimentos. Recuperado de https://www.who.int/foodsafety/areas work/zoonose/es/.

Patterson, Charles. (2002). Eternal treblinka: our treatment of animals and the Holocaust. Nueva York: Lantern Books. 
Programa Universitario de Bioética UNAM. (2020, 17 de septiembre). El árbol de las ideas T3-C1 "Educación y medio ambiente" [Archivo de video]. Recuperado de https://youtu.be/FdxHKZgPQOU.

Radio UNAM (productora). (s. f.). 103 Arbol Ideas Sustentabilidad Ambiental M020920 (Serie "El árbol de las ideas") (podcast). Recuperado de https://www. radiopodcast.unam.mx/podcast/audio/24014.

SinozA, Baruch. (2020). Ética demostrada según el orden geométrico. Madrid: Trotta.

Trapp Caroline B.; BARNARd Neal D. (2010). "Usefulness of vegetarian and vegan diets for treating type 2 diabetes". Current Diabet Reports, 10(2), 152-158. http://doi.org/10.1007/s11892-010-0093-7. 